\title{
Modeling microphysical effects of entrainment in clouds observed during EUCAARI-IMPACT field campaign
}

\author{
D. Jarecka ${ }^{1}$, H. Pawlowska ${ }^{1}$, W. W. Grabowski ${ }^{2}$, and A. A. Wyszogrodzki ${ }^{2}$ \\ ${ }^{1}$ Institute of Geophysics, Faculty of Physics, University of Warsaw, Warsaw, Poland \\ ${ }^{2}$ National Center for Atmospheric Research, Boulder, Colorado, USA
}

Correspondence to: D. Jarecka (dorota@igf.fuw.edu.pl)

Received: 13 December 2012 - Published in Atmos. Chem. Phys. Discuss.: 15 January 2013

Revised: 15 July 2013 - Accepted: 19 July 2013 - Published: 27 August 2013

\begin{abstract}
This paper discusses aircraft observations and large-eddy simulation (LES) modeling of 15 May 2008, North Sea boundary-layer clouds from the EUCAARIIMPACT field campaign. These clouds are advected from the northeast by the prevailing lower-tropospheric winds and featured stratocumulus-over-cumulus cloud formations. An almost-solid stratocumulus deck in the upper part of the relatively deep, weakly decoupled marine boundary layer overlays a field of small cumuli. The two cloud formations have distinct microphysical characteristics that are in general agreement with numerous past observations of strongly diluted shallow cumuli on one hand and solid marine stratocumulus on the other.

Based on the available observations, a LES model setup is developed and applied in simulations using a novel LES model. The model features a double-moment warm-rain bulk microphysics scheme combined with a sophisticated subgrid-scale scheme allowing local prediction of the homogeneity of the subgrid-scale turbulent mixing. The homogeneity depends on the characteristic time scales for the droplet evaporation and for the turbulent homogenization. In the model, these scales are derived locally based on the subgrid-scale turbulent kinetic energy, spatial scale of cloudy filaments, mean cloud droplet radius, and humidity of the cloud-free air entrained into a cloud, all predicted by the LES model. The model reproduces contrasting macrophysical and microphysical characteristics of the cumulus and stratocumulus cloud layers. Simulated subgrid-scale turbulent mixing within the cumulus layer and near the stratocumulus top is on average quite inhomogeneous, but varies significantly depending on the local conditions.
\end{abstract}

\section{Introduction}

The impact of cloud entrainment on the spectrum of cloud droplets remains poorly understood because of difficulties encountered in cloud observations and the limited range of spatial scales resolved in numerical modeling. Entrainment typically leads to reduction of the cloud liquid water content (LWC), but microphysical effects can vary widely. In the homogeneous mixing case, the dilution leads to the reduction of the droplet size, with the decrease of droplet concentration only due to the changes of the total cloudy volume. When the extremely inhomogeneous mixing takes place, the droplet concentration is reduced without effects on the droplet radius. Both droplet radius and concentration are reduced in the intermediate case of the inhomogeneous mixing. The homogeneity of mixing has been argued to depend on the relative magnitude of the time scales for droplet evaporation and for turbulent homogenization (Baker and Latham, 1979; Baker et al., 1980; Jensen and Baker, 1989; Burnet and Brenguier, 2007; Andrejczuk et al., 2009; Lehmann et al., 2009). Homogeneous mixing takes place when the turbulent homogenization time scale is much smaller than the droplet evaporation time scale because then all droplets are exposed to the same conditions during evaporation. At the opposite limit, when the turbulent homogenization time scale is much larger than the droplet evaporation time scale, extremely inhomogeneous mixing is thought to occur. At such a limit, some droplets evaporate completely and the rest do not experience any evaporation at all.

There is a large gap between scales resolved by a traditional large-eddy simulation (LES) model $(\sim 10 \mathrm{~m}$ and larger) and scales at which the microscale homogenization takes place (close to the Kolmogorov microscale, $\sim 10^{-3} \mathrm{~m}$ 
in typical atmospheric conditions). Because of the gap, homogenization of a coarsely mixed volume of the size comparable to the LES model gridbox does not take place instantaneously. Instead, a significant delay of the homogenization is expected due to turbulent stirring. Turbulent stirring refers to the process where an initially coarsely mixed and partially cloudy volume gradually evolves towards microscale homogenization (see discussion in Grabowski, 2007). Arguably, early stages of the turbulent stirring are associated with the extremely inhomogeneous mixing because only the droplets near filament edges evaporate completely (i.e., the mean droplet concentration is reduced without changing the mean droplet size). As the stirring progresses, the mean size of cloudy filaments decreases and eventually approaches the Kolmogorov microscale where the microscale homogenization takes place. At this stage, all droplets are exposed to the same subsaturation and mixing approaches the homogeneous limit. Modeling of such a chain of events requires a special subgrid-scale turbulent stirring scheme, for instance, as proposed in Grabowski (2007) and further developed in Jarecka et al. (2009).

Jarecka et al. (2013, hereinafter JGMP13) merge the delayed evaporation (stirring) scheme with the double-moment bulk warm-rain microphysics scheme to allow prediction of the local mixing scenario. The resulting LES model equipped with the subgrid-scale stirring/evaporation scheme is applied to the Barbados Oceanographic and Meteorological Experiment (BOMEX) shallow convection case (Siebesma et al., 2003). Herein, the same model is set to simulate the cloud case observed during the EUCAARI-IMPACT (European Integrated Project on Aerosol Cloud Climate and Air Quality Interactions - Intensive Observation Period At Cabauw Tower) field project. The case is attractive because it features cumulus-under-stratocumulus cloud formations with contrasting microphysical characteristics in either one. Small cumuli are typically strongly diluted, with turbulent entrainment occurring mostly through cloud lateral boundaries. In contrast, the almost-solid stratocumulus deck is typically close to adiabatic with the exception of its very top where entrainment of the air from above the inversion takes place.

There are three main themes in this study. First, based on available observations and guided by methodologies used in previous investigations (e.g., Siebesma et al., 2003; Stevens et al., 2005), we design a LES case of stratocumulus-overcumulus in the midlatitudes. Second, we evaluate the performance of the JGMP13 model under such conditions and compare it to the performance of a traditional LES model (i.e., without the stirring/evaporation scheme). Third, we study simulated microphysical effects of entrainment and mixing, and contrast the lateral cumulus mixing with the stratocumulus top mixing. The next section briefly describes the specific case from the EUCAARI-IMPACT campaign selected for the modeling study. Section 3 provides details of the LES model and modeling setup. Characteristics of simulated cloud field and comparison with the observations are

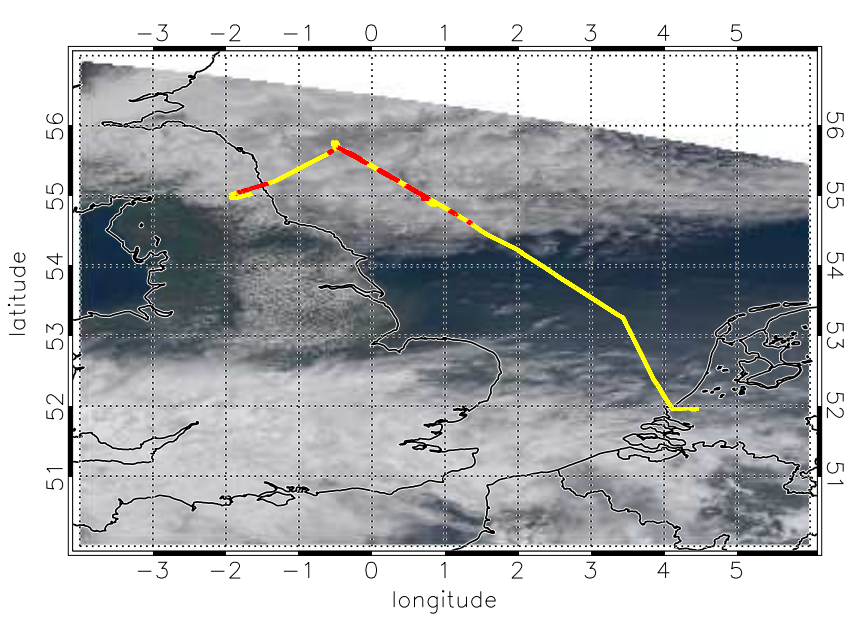

Fig. 1. Image from the Moderate Resolution Imaging Spectroradiometer (MODIS) system (Terra satellite, 11:15 UTC). Yellow line shows the trajectory of the ATR-42 morning flight on 15 May. Red segments indicate periods where aircraft encountered a cloud.

presented in Sect. 4, and simulated mixing characteristics in Sect. 5. Section 6 briefly discusses results from the standard LES model. A summary in Sect. 7 concludes the paper.

\section{The EUCAARI-IMPACT field campaign and 15 May North Sea case}

The IMPACT (Intensive Observation Period At Cabauw Tower) field campaign was a part of the EUCAARI (European Integrated Project on Aerosol Cloud Climate and Air Quality Interactions; Kulmala et al., 2011) project funded under the EU Framework Programme 6. The campaign took place in May 2008 in the Netherlands and focused on remote sensing and in situ ground-based and airborne observations of clouds and aerosols in the vicinity of the Cabauw tower. Because of unexpectedly dry and cloudless conditions that prevailed over the Netherlands for most of the EUCAARIIMPACT campaign, several scientific flights were conducted over the North Sea. These flights targeted clouds and aerosols within the stratocumulus-topped marine boundary layer. The 15 May flight was one of such cases (Puygrenier et al., 2010).

Figure 1 shows flight trajectory of 15 May Meteo-France Safire ATR-42 mission superimposed on the MODIS (Moderate Resolution Imaging Spectroradiometer) satellite image at 11:15 UTC. The figure shows a significant cloud cover over the North Sea and the surrounding land masses. Shallow convective clouds over eastern England, just to the west of the Greenwich meridian, document the lowlevel northeasterly flow over the region, in agreement with the aircraft data (not shown). The stratocumulus deck over the North Sea extends to the north of approximately the $54^{\circ} \mathrm{N}$ parallel and appears quite spatially heterogeneous. The stratocumulus-topped boundary layer (STBL) and the lower 


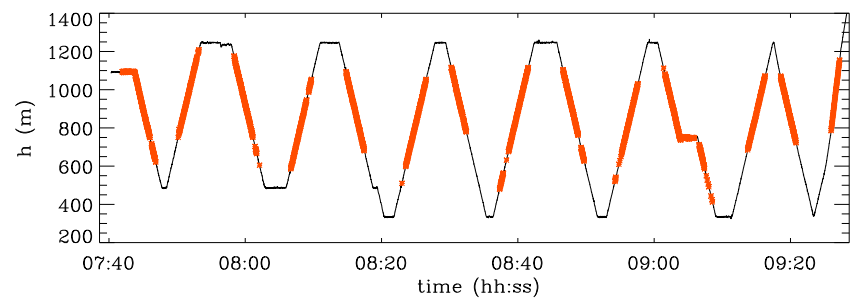

Fig. 2. Height of the aircraft ATR-42 as a function of time. Red color marks periods when aircraft encountered a cloud.

free troposphere were sampled by the aircraft between approximately 07:40 and 09:30 UTC. Figure 2 shows the height of the aircraft as a function of time and depicts in red periods when the aircraft encountered a cloud. The figure shows that besides the stratocumulus cloud (with cloud base and cloud top around 700 and $1150 \mathrm{~m}$ ), the aircraft often intersected clouds beneath the stratocumulus cloud base. Such a situation, often referred to as the boundary layer with cumulus under stratocumulus, corresponds to a weakly decoupled, relatively deep marine boundary layer, often associated with the transition from shallow STBL to significantly deeper cumulus-topped boundary layer in the subtropics (see Bretherton and Pincus, 1995; de Roode and Duynkerke, 1997; Sandu et al., 2010).

The cloud data from the flight track shown in Figs. 1 and 2 are divided into two sets depending on the height of the aircraft to represent the stratocumulus and cumulus clouds. The droplet concentration, cloud water mixing ratio, and mean volume radius for the two cloud types are shown in Figs. 3 and 4. Each data point in the figures represents approximately $100 \mathrm{~m}$ average $(1 \mathrm{~Hz})$ of cloud droplet counts from the FFSSP (Fast Forward Scattering Spectrometer Probe; Brenguier et al., 1998). The data corresponding to the stratocumulus cloud (Fig. 3) are shown as a function of height above the cloud base that is estimated separately for each cloud penetration and varies between $650 \mathrm{~m}$ and $750 \mathrm{~m}$. Figure 3 shows a fairly typical pattern: approximately constant with height droplet concentration $\left(\sim 100 \mathrm{mg}^{-1}\right.$; except near the cloud base where the FFSSP may miss small droplets and near cloud top where intensive mixing takes place), the cloud water mixing ratio not far from the adiabatic (but also with a significant spread, especially in the upper half of the cloud depth), and the mean volume radius increasing gradually with height and consistent with the observed concentrations. In contrast, the data for the cumuli (Fig. 4) show a wide range of droplet concentrations and relatively small values of the cloud water mixing ratio. The mean volume radius is small, in the range of 2 to $8 \mu \mathrm{m}$, as in the lower part of the stratocumulus. All these suggest that small cumuli beneath stratocumulus are strongly diluted and the $1 \mathrm{~Hz}$ data may not represent the small-scale features adequately. Because cumulus cloud fraction is low, there is a significantly lower number of data points in Fig. 4 compared to Fig. 3. Some of these cu- muli are likely to penetrate into the stratocumulus layer; this may explain data points with cloud water exceeding the adiabatic value in Fig. 3b. These observations will guide the discussion of microphysical effects resulting from the turbulent entrainment in simulated cumulus and stratocumulus clouds.

\section{The numerical model, model setup, and model simulations}

The model used in the simulations is the same as in JGMP13. The fluid flow model is the 3-D anelastic semi-Lagrangian/Eulerian model EULAG documented in Smolarkiewicz and Margolin (1997, model dynamics), Grabowski and Smolarkiewicz (1996, model thermodynamics), and Margolin et al. (1999, subgrid-scale turbulent mixing). Prusa et al. (2008) provide a recent review with the comprehensive list of references. As in JGMP13, EULAG is set up as a LES model with the horizontal/vertical gridlength of $50 / 20 \mathrm{~m}$ and the computational domain of $6.4 / 3 \mathrm{~km}$ in the horizontal/vertical direction. The resolution is relatively low, but the model applies a sophisticated subgrid-scale mixing scheme that mitigates to some extent effects of the low spatial resolution ${ }^{1}$. Periodic lateral boundary conditions are used, and free-slip rigid lid boundaries are assumed at the bottom and top boundaries. Model time step is $1 \mathrm{~s}$. The model is run for $6 \mathrm{~h}$, and snapshots of model fields saved every $3 \mathrm{~min}$ from the last $3 \mathrm{~h}$ of the simulation are used in the analysis.

Model thermodynamics combines the two-moment warmrain scheme (i.e., predicting both the mixing ratio and the droplet concentration for the cloud and rain water; Morrison and Grabowski, 2007, 2008) with the delay of cloud water evaporation resulting from the subgrid-scale mixing between the cloud and its environment (Grabowski, 2007; Jarecka et al., 2009). Activation of cloud droplets is represented by the approach developed by Khvorostyanov and Curry (2006) with the total CCN concentration set to $200 \mathrm{mg}^{-1}$. The latter is based on EUCAARI-IMPACT observations reported in Crumeyrolle et al. (2011). Autoconversion and accretion parameterization follow those proposed in Khairoutdinov and Kogan (2000) as used in Morrison and Grabowski (2007). The delay of cloud water evaporation during turbulent mixing is facilitated by predicting two additional model variables, the characteristic scale (width) $\lambda$ of cloud filaments and the fraction of gridbox volume occupied by the cloudy air $\beta$. The scale $\lambda$ is assumed to decrease during the stirring phase of the entrainment process from the scale of an initial engulfment $\Lambda$ (assumed to be of the order of the model gridlength) down to the scale of microscale homogenization

\footnotetext{
${ }^{1}$ Decreasing the vertical gridlength alone as often done in LES stratocumulus studies (e.g., Stevens et al., 2005; Kurowski et al., 2009) leads to a large heterogeneity of the model grid that is difficult to incorporate in subgrid-scale schemes. Simulations with higher spatial resolution in all three directions are outside the scope of this study and need to be considered in the future.
} 

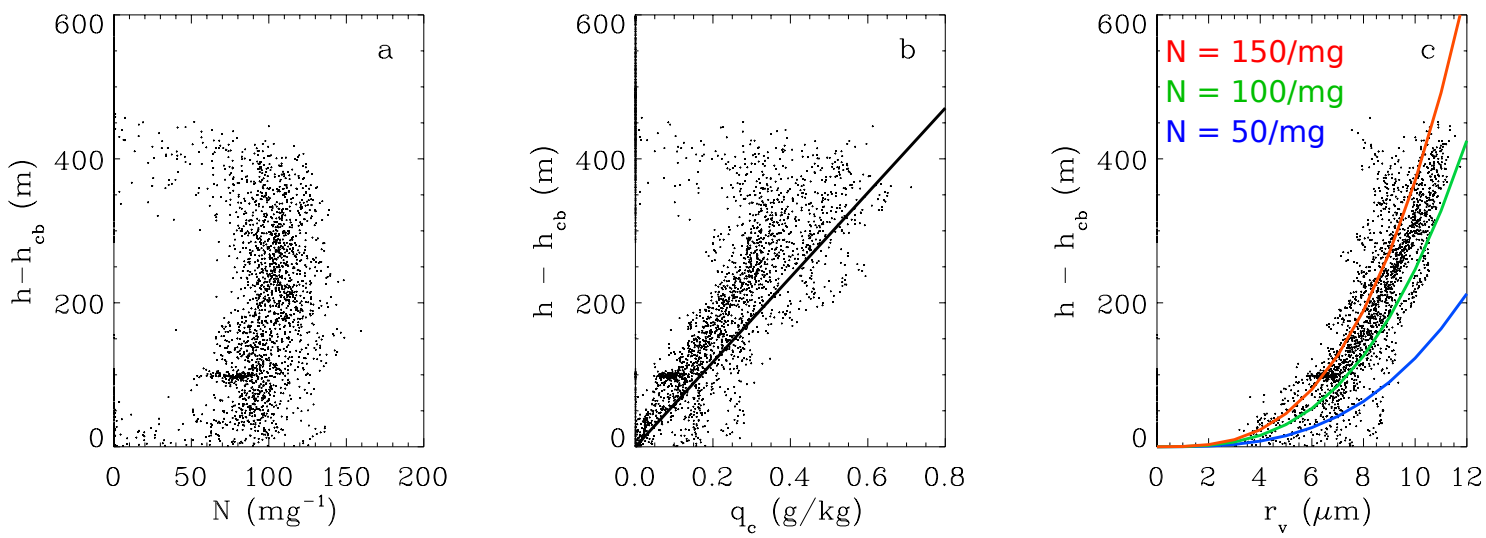

Fig. 3. Experimental data from the stratocumulus cloud layer. (a) Cloud droplet concentration; (b) cloud water mixing ratio; (c) droplet mean volume radius. Vertical axes represent height above the cloud base $h_{\mathrm{cb}}$ estimated separately for each cloud penetration by fitting the theoretical function of adiabatic LWC to the experimental data. Color lines in (c) mark profiles of the adiabatic droplet radius for different droplet concentration.
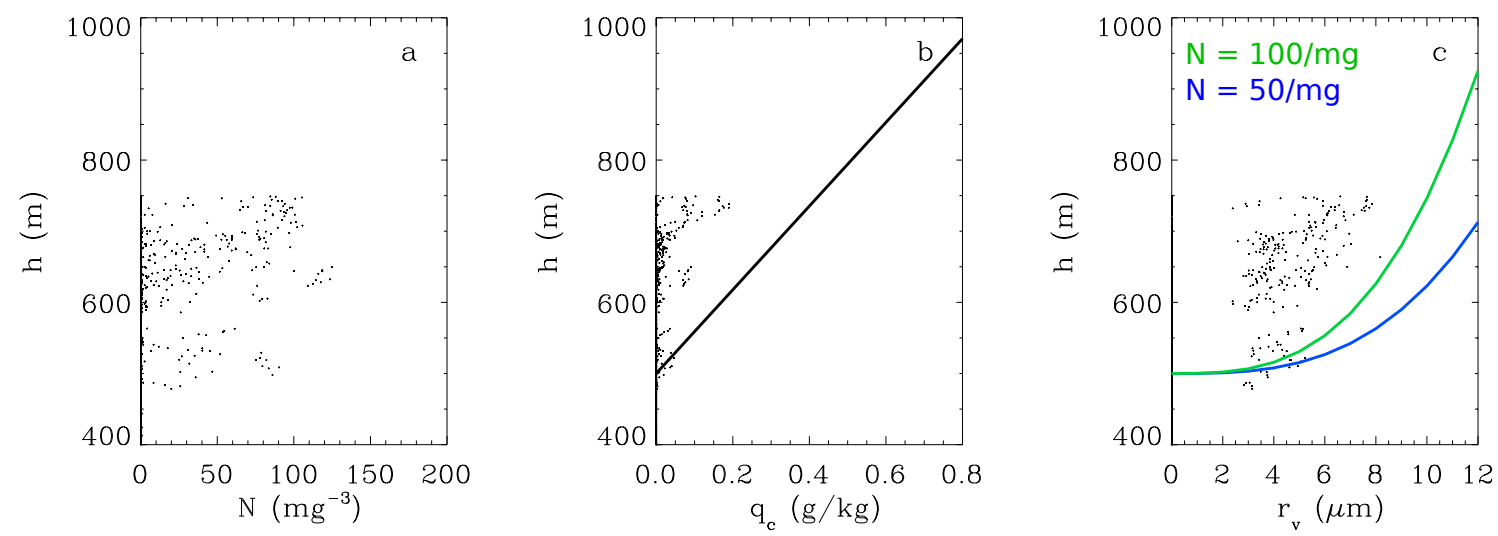

Fig. 4. As Fig. 3 but for the cumulus cloud layer. Vertical axes represent height above the sea level.

$\lambda_{0}$ (i.e., of the order of the Kolmogorov microscale; $\sim 1 \mathrm{~mm}$ in atmospheric conditions). The evaporation of cloud water due to subgrid-scale mixing depends on the scale $\lambda$, with virtually no evaporation when $\lambda \sim \Lambda$, and all evaporation when $\lambda \sim \lambda_{0}$ (see discussion in Grabowski, 2007).

In the double-moment scheme the homogeneity of mixing is controlled by the parameter $\alpha$ (Morrison and Grabowski, 2008). The parameter $\alpha$ is calculated locally based on the predicted turbulent kinetic energy (TKE), the scale of cloud filaments $\lambda$, mean cloud droplet radius, and the humidity of the cloud-free air entrained into the cloud. Results of direct numerical simulations of the interfacial cloudy and cloudfree air mixing reported in Andrejczuk et al. (2009) are used in the prediction of $\alpha$. See Appendix A and JGMP13 for more details.

The entire thermodynamics/microphysics scheme operates in the following way. For a gridbox with either $\lambda=\Lambda$ or $\lambda=0-$ that is, either fully cloudy or cloud-free, respectively - calculations progress as in the standard double-moment scheme of Morrison and Grabowski $(2007,2008)$ without any subgrid-scale considerations. For a gridbox with $\lambda_{0}<$ $\lambda<\Lambda$, the expected evaporation or condensation of cloud water $\delta q_{\mathrm{c}}$ is calculated first using the grid-averaged fields as in the standard double-moment scheme. If condensation is predicted, then the gridbox is assumed uniform, $\delta q_{\mathrm{c}}$ is applied in the microphysics scheme, $\lambda$ is reset to $\Lambda$ and $\beta$ is reset to 1 . The same procedure is used when $\lambda<\lambda_{0}$ because molecular homogenization is assumed to be completed. If needed, activation of new cloud droplets takes place. For the evaporation, $\delta q_{\mathrm{c}}$ is first partitioned into the adiabatic part $\beta C^{\text {ad }} \Delta t$ [where $C^{\text {ad }}$ is the adiabatic condensation rate (see appendix in Grabowski (2007)) and $\Delta t$ is the model time step] and the contribution due to mixing $\Delta q_{\mathrm{c}}$ assuming $\Delta q_{\mathrm{c}}=\delta q_{\mathrm{c}}-\beta C^{\text {ad }} \Delta t$. Note that variable $\Delta q_{\mathrm{c}}$, which is a part due to diabatic evaporation, combines impacts of the explicit diffusion (due to turbulent mixing terms) as well as the implicit (numerical) diffusion. Because of the delay of the diabatic evaporation during the stirring phase of the entrainment, only a fraction of $\Delta q_{\mathrm{c}}, \Delta q_{\mathrm{c}}^{*}=\lambda_{0} / \lambda \Delta q_{\mathrm{c}}$, is allowed to evaporate. This formula comes from heuristic considerations 


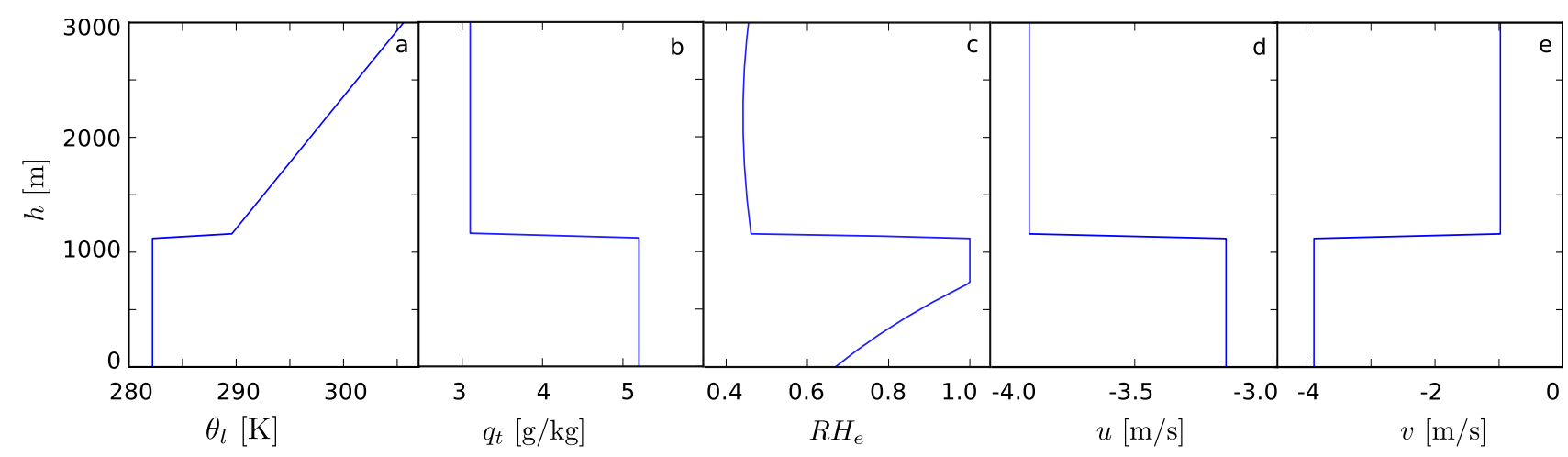

Fig. 5. Idealized profiles of observed mean conditions used to initialize the simulation. (a) Liquid water potential temperature $\theta_{1}$; (b) total cloud water mixing ratio $q_{\mathrm{t}}$; (c) relative humidity $\mathrm{RH}_{\mathrm{e}}$; (d) zonal wind $u$; (e) meridional wind $v$.

concerning droplet evaporation at the edges of cloud filaments. Next, $\Delta q_{\mathrm{c}}^{*}$ is applied to the cloud water mixing ratio, and the droplet concentration is reduced depending on the homogeneity of the subgrid-scale mixing, that is, through the parameter $\alpha$ (see Appendix A). In addition, the adiabatic condensation $C^{\text {ad }}$ is applied to the $\beta$ cloudy fraction of the gridbox assuming no change in the droplet concentration.

Because there is no tested LES setup for the meteorological situation observed on 15 May, initial profiles and forcings are obtained by considering available field data and applying modeling approaches used in similar studies (e.g., Siebesma et al., 2003; Stevens et al., 2005) in test simulations. The idealization of observed mean conditions used to initialize the simulation is shown in Fig. 5. The total water mixing ratio, liquid water potential temperature and horizontal wind components are taken as $5.2 \mathrm{~g} \mathrm{~kg}^{-1}, 282.2 \mathrm{~K}$, -3.18 and $-3.89 \mathrm{~m} \mathrm{~s}^{-1}(\mathrm{E}-\mathrm{W}$ and $\mathrm{N}-\mathrm{S}$ ) up to the base of the STBL inversion at $1120 \mathrm{~m}$. The inversion is assumed to be $40 \mathrm{~m}$ deep, with the profiles linearly changing to $3.1 \mathrm{~g} \mathrm{~kg}^{-1}$, $289.6 \mathrm{~K},-3.87$ and $-0.98 \mathrm{~m} \mathrm{~s}^{-1}$ at $1160 \mathrm{~m}$. Above, the liquid water potential temperature (equal to the potential temperature in absence of cloud condensate) increases linearly to $305.6 \mathrm{~K}$ at $3 \mathrm{~km}$ (i.e., the model top), whereas all other fields are assumed constant with values as at the inversion top.

The model is forced to maintain approximately steadystate conditions throughout the simulation, similarly to other LES boundary layer studies (e.g., Siebesma et al., 2003; Stevens et al., 2005). Forcings required to maintain approximately steady-state conditions are estimated by trial-anderror test simulations. The forcings include (a) surface heat and momentum fluxes; (b) large-scale subsidence; and (c) radiative processes. Surface heat fluxes and subsidence are assumed to be constant in time and space. Surface sensible and latent heat fluxes are derived by applying the estimation of the sea surface temperature (SST) from the satellite analysis for this day. After some tests, the values are selected as constant $8 \times 10^{-3} \mathrm{~K} \mathrm{~m} \mathrm{~s}^{-1}$ for the sensible heat flux and $6.5 \times 10^{-5} \mathrm{~m} \mathrm{~s}^{-1}$ for the latent heat flux. The surface momentum fluxes are calculated similarly to Siebesma et al. (2003), with the fluxes given by $-u_{*}^{2} \mathbf{v} /|\mathbf{v}|$, with $u_{*}=0.28 \mathrm{~m} \mathrm{~s}^{-1}$. Large-scale subsidence is prescribed as $W_{\mathrm{s}}=-D z$ with the large-scale divergence selected as $D=4 \times 10^{-6} \mathrm{~s}^{-1}$. For the radiative transfer, only the longwave processes are considered as the key driver of the STBL dynamics and only in the extremely simplified way as proposed in Stevens et al. (2005, see Eqs. 3 and 4 there). The parameters in the simple approach are the same as in Stevens et al. (2005) except for the parameter controlling the cooling in the free atmosphere, $\alpha_{z}$, which is taken as half of the value given in Stevens et al. (2005), that is, $\alpha_{z}=0.5 \mathrm{~m}^{-4 / 3}$. Surface pressure is assumed to be $1015 \mathrm{hPa}$.

\section{Simulated cloud field characteristics}

Evolutions of the selected bulk STBL properties for the entire length of the simulation are presented in Fig. 6. The figure documents significant fluctuations of the liquid water path (not atypical for such simulations; see Fig. 2 in Stevens et al., 2005), gradual decrease of the resolved kinetic energy, and about $80 \mathrm{~m}$ increase of the inversion height. The latter implies that prescribed large-scale subsidence does not balance the increase of the inversion height due to the boundary-layer entrainment. The figure shows that the proposed LES setup only approximately maintains the steady-state conditions.

To illustrate model results, Fig. 7 shows snapshots of the cloud water field in the two vertical cross sections of the computational domain at time of $t=6 \mathrm{~h}$, i.e., at the end of the simulation. Black lines represent isolines of the cloud water mixing ratio. Similarly to the observations, the simulated stratocumulus overlays a layer with shallow convective clouds that either grow into the stratocumulus layer (like the cloud near the center of the upper panel) or remain detached in the layer between 400 and $700 \mathrm{~m}$ (see the bottom panel). Such a situation is typical for relatively deep STBL and results from weak decoupling between the two cloud layers (see Bretherton and Pincus, 1995; de Roode and Duynkerke, 1997; Sandu et al., 2010). The color scale indicates the local 


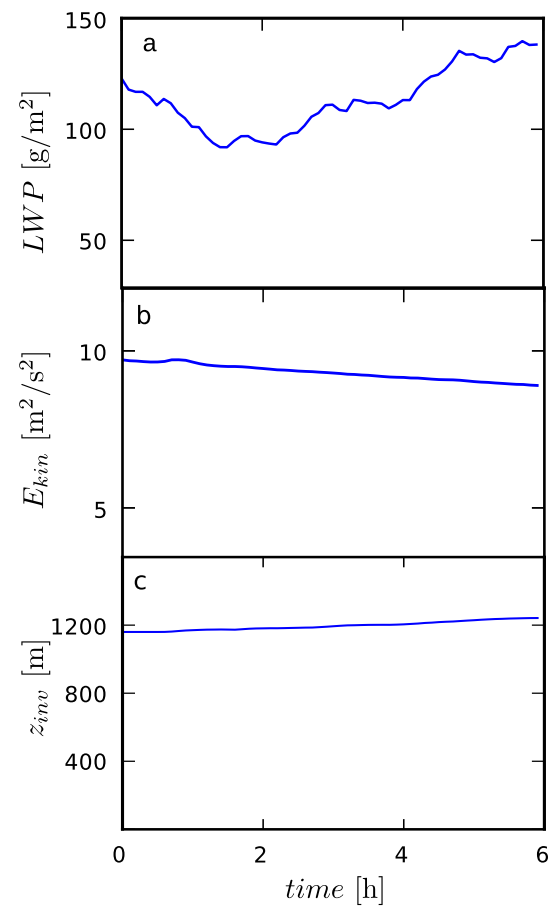

Fig. 6. Evolution of the selected bulk properties of the STBL for the entire length of the simulation. (a) Liquid water path (LWP); (b) resolved kinetic energy per unit of mass $E_{\text {kin }}$; (c) height of the inversion $z_{\text {inv }}$.

values of the parameter $\alpha$ at the points undergoing subgridscale turbulent cloud-environment mixing. The figure shows that parameterized mixing occurs typically at the edges of cumulus clouds and at the stratocumulus top. Some cloudenvironment mixing takes place at "cloud holes" (i.e., breaks in the stratocumulus deck) as illustrated in the bottom panel. Mixing characteristics, that is, the parameter $\alpha$, vary significantly at various locations, from close to homogeneous ( $\alpha=0$, dark blue colors) to not far from extremely inhomogeneous ( $\alpha=1$, dark red colors).

The double-layer structure of clouds within STBL is also suggested by the mean cloud fraction and in-cloud condensed water profiles (Fig. 8). To obtain these profiles, gridpoints of the model data are assumed cloudy if the cloud water mixing ratio exceeds $0.01 \mathrm{~g} \mathrm{~kg}^{-1}$ and the droplet concentration exceeds $5 \mathrm{mg}^{-1}$. The cloud fraction within the cumulus layer is small $(\sim 0.1)$, but it is quite high, up to 0.9 , within the stratocumulus layer. The profile of the cloud water mixing ratio shows that clouds within the cumulus layer (roughly between 300 and $700 \mathrm{~m}$ above the sea level) are significantly diluted by entrainment. The mean cloud water mixing ratio increases with height at the rate much lower than the adiabatic one (the latter is $\sim 0.8 \mathrm{~g} \mathrm{~kg}^{-1}$ per $500 \mathrm{~m}$ and shown by black dashed lines in the figure). The rate of increase of the cloud water mixing ratio within the stratocumulus layer is significantly higher and not far from the adiabatic one. The reduction of the cloud water near the cloud top comes from the cloud-top entrainment as illustrated by the number of gridpoints undergoing turbulent mixing (see colored points in Fig. 7). Overall, the behavior of the in-cloud profiles of the cloud water mixing ratio is similar to the observations (Figs. 3 and 4).

Cumulus and stratocumulus cloud layers exhibit different microphysical characteristics. Figure 9 shows the contoured frequency-by-altitude diagram (CFAD; the probability density function calculated at each height and applying colors to mark the frequency of occurrence) of the cloud droplet concentration. The red line shows the average profile. Only cloudy gridpoints are included in the analysis, and the cloud fraction profile is shown by the blue line on the right-hand side of the figure. The mean values of cloud droplet concentration inside the layers are approximately constant except layers close to the cloud top, cloud base and the transition part between cumulus and stratocumulus. The mean concentration for the stratocumulus layer is around $90 \mathrm{mg}^{-1}$, and it is around $60 \mathrm{mg}^{-1}$ for the cumulus layer. These are in good agreement with observational values (see Fig. 3 and 4). The figure shows a large spread inside the cumulus layer, with the most frequent values around $20 \mathrm{mg}^{-1}$ and some points with concentrations as high as $160 \mathrm{mg}^{-1}$. Because of the strongly skewed distribution, the mean and the most frequent values differ significantly. The distribution narrows within the stratocumulus layer, and the most frequent values are close to the mean. The increase of the distribution width near the top of the stratocumulus layer (i.e., above the level of $1100 \mathrm{~m}$ ) comes from the mixing with the unsaturated air from above the cloud top.

The fraction of gridbox volume occupied by the cloudy air $\beta$ is shown in Fig. 10. As expected, $\beta$ is seldom different from unity within the stratocumulus layer, implying uniform cloudy volumes. In contrast, $\beta$ varies widely within the cumulus layer and near the stratocumulus top where entrainment and mixing take place. Although difficult to compare with the field observations, these results seem consistent with the physical processes within the two cloud layers. The wide range of $\beta$ implies that the predicted gridbox-averaged droplet concentration $N$ and the droplet concentration within the cloudy part of the gridbox volume $N / \beta$ (the latter referred to as the local droplet concentration) differ significantly. The differences between the $N$ and $N / \beta$ are highlighted in the Fig. 11. The figure presents the $N-N / \beta$ scatter diagrams for the height of $500 \mathrm{~m}$ (i.e., within the cumulus layer) and $1200 \mathrm{~m}$ (i.e., near the stratocumulus top) with color marking vertical velocity. The points on the diagonal of the diagrams correspond to $\beta=1$ and therefore to alreadyhomogenized cloudy volumes. For the cumulus, the diagram resembles the diagram for shallow convection from JGMP13 (cf. Fig. 9 therein). Cloudy volumes with droplet concentrations larger than about $50 \mathrm{mg}^{-1}$ are typically uniform $(\beta=$ 1) with positive vertical velocities. Cloudy volumes with smaller droplet concentrations are often inhomogeneous with a wide range of $\beta$ values and vertical velocities close to zero. 

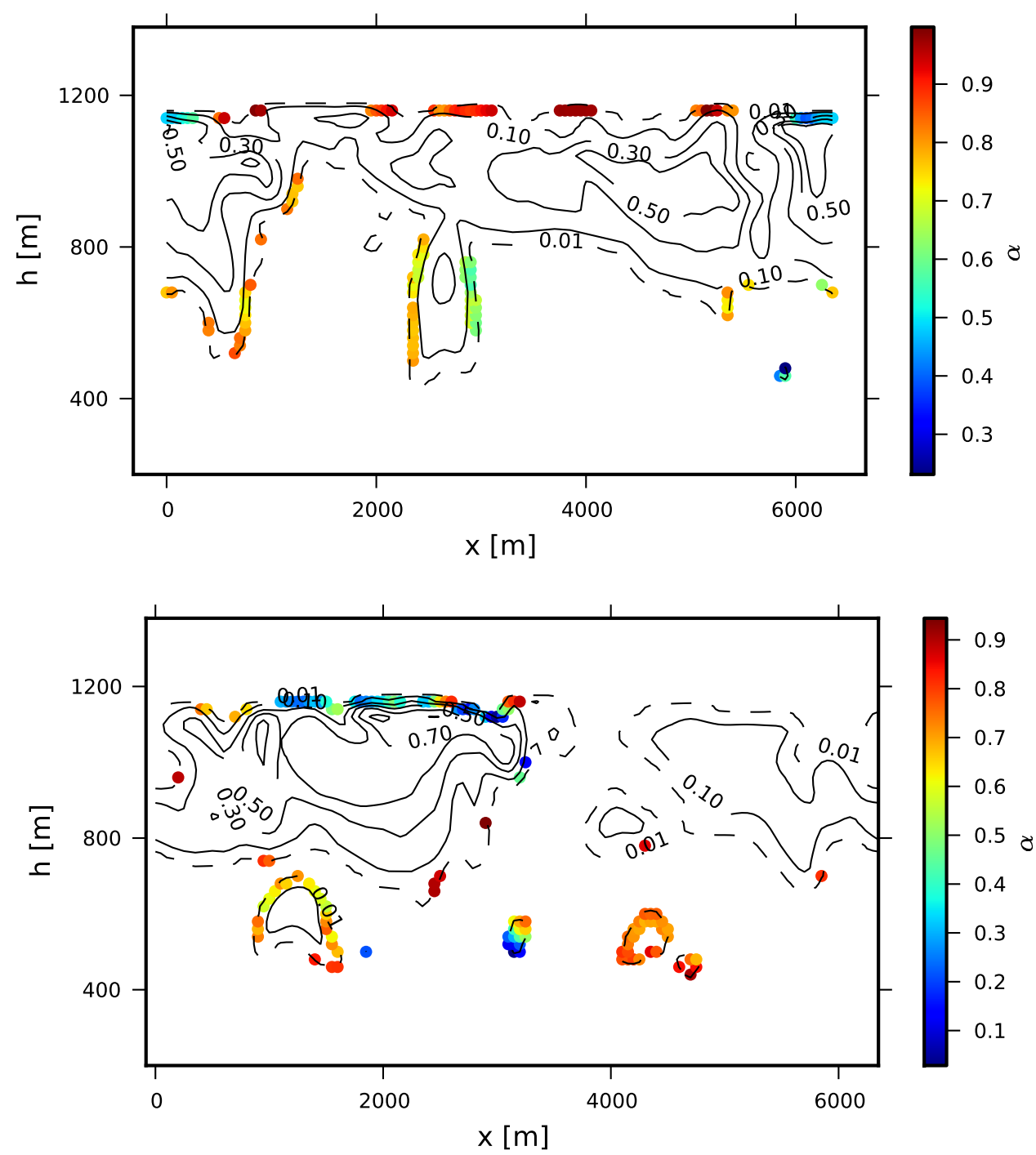

Fig. 7. Snapshots of the cloud water field in two vertical cross sections of the computational domain at time of $t=6 \mathrm{~h}$. Black solid lines show isolines of the cloud water mixing ratio; $0.01 \mathrm{~g} \mathrm{~kg}^{-1}$ isoline is shown by the dashed line. Color marks local values of the parameter $\alpha$ at the points undergoing turbulent cloud-environment mixing.

In contrast, the diagram for cloudy volumes near the stratocumulus top shows a different picture. In addition to homogenized $\beta=1$ volumes with upward velocities, high values of local droplet concentration $N / \beta$ can be also found in strongly inhomogeneous volumes with a wide range of $\beta$ values and negative velocities. The strongest downward velocities (i.e., dark blue colors in Fig. 11) are usually in volumes with the highest local droplet concentration. Arguably, these highly inhomogeneous descending volumes near the stratocumulus top represent initial stages of entrainment and mixing, where the close-to-adiabatic air within the stratocumulus impinges upon the inversion, mixes with the cloudfree air from the inversion layer, and is forced back into the main stratocumulus deck (see discussion in Kurowski et al., 2009).
CFAD of the cloud droplet mean volume radius $r_{\mathrm{v}}$ (Fig. 12) further supports decoupling of the two cloud layers, in agreement with observations (cf. Figs. 3 and 4). The most frequent $r_{\mathrm{v}}$ values increase with height in both layers, and the separation between the layers is evident. The green lines show the adiabatic values of the radius assuming the cloud base height and the adiabatic droplet concentration of $300 \mathrm{~m}$ and $60 \mathrm{mg}^{-1}$ for the cumulus layer, and $700 \mathrm{~m}$ and $90 \mathrm{mg}^{-1}$ for the stratocumulus layer. In the stratocumulus layer, the most frequent values are close to the adiabatic profile. This indicates that the stratocumulus is only weakly diluted by entrainment, the aspect consistent with the observations (Fig. 3). For the cumulus layer, the most frequent values are much smaller than adiabatic (except near the cloud base) with radii smaller than $8 \mu \mathrm{m}$. Similar behavior is seen 


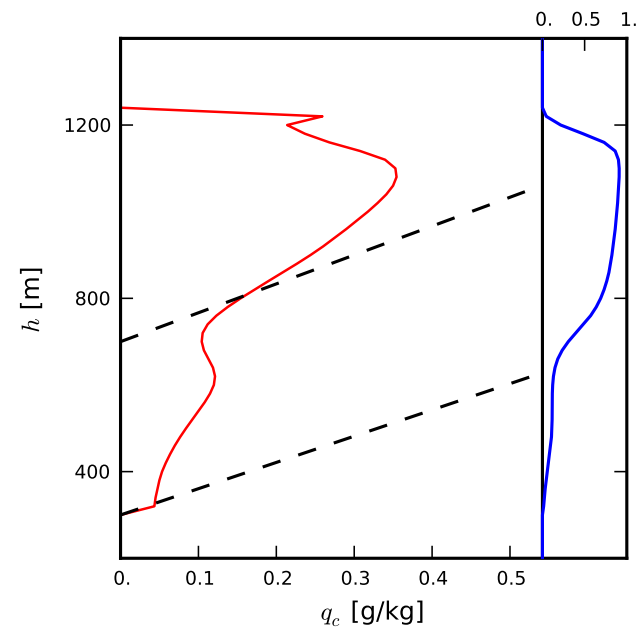

Fig. 8. Average profiles of the conditionally sampled in-cloud cloud water mixing ratio. The black dashed lines show the adiabatic liquid water content for cumulus and stratocumulus layers assuming cloud base at height 300 and $700 \mathrm{~m}$, respectively. The cloud fraction profile is shown on the right-hand side of the panel with the blue line.

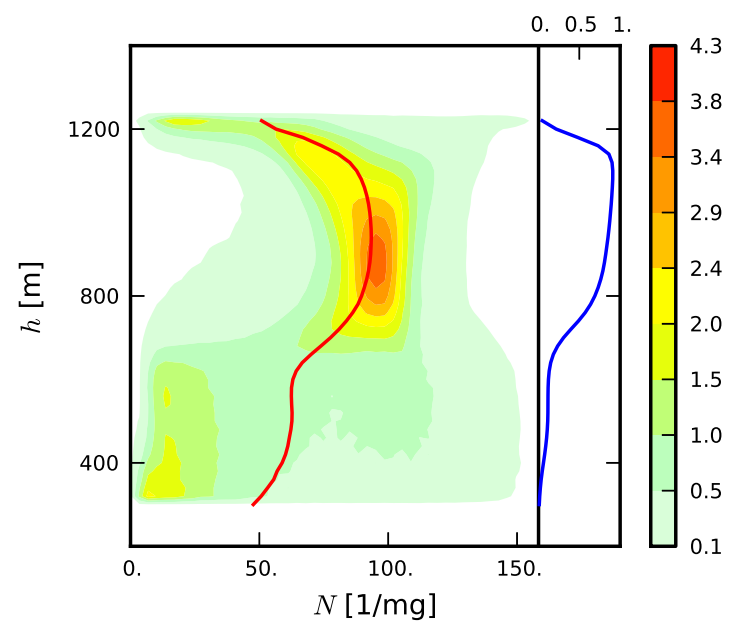

Fig. 9. CFAD of the cloud droplet concentration $N$; only cloudy points are included. Red line shows the average profile. The cloud fraction profile is shown on the right-hand side of the panel with the blue line.

in the observations (see Fig. 4). This is the consequence of strong dilution of cumulus clouds. Although some cumuli penetrate into stratocumulus layer (see examples in Fig. 7) Fig. 12 clearly shows that this is not the dominant pattern.

\section{Subgrid-scale mixing characteristics}

The subgrid-scale stirring/evaporation scheme developed in JGMP13 predicts locally the mixing scenario at each time step by deriving the parameter $\alpha$ from model variables (see Appendix A). Possible values of the parameter $\alpha$ range from

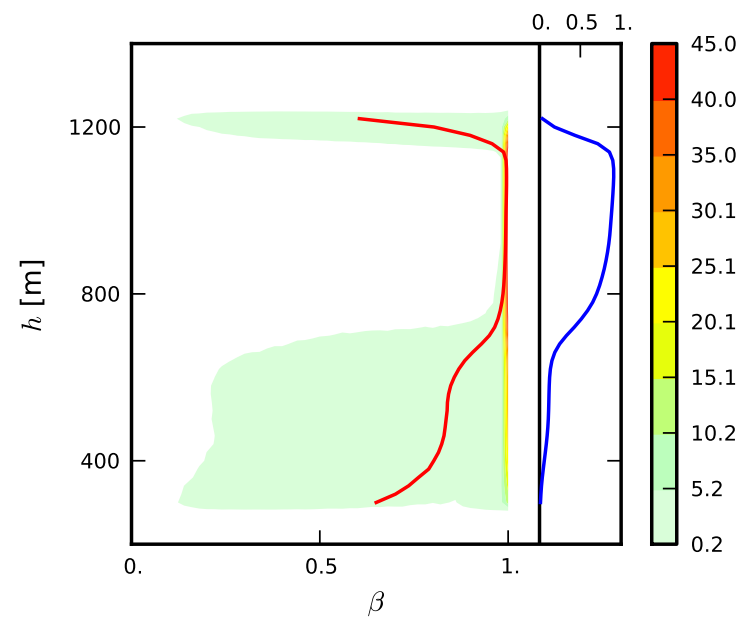

Fig. 10. CFAD of the fraction of gridbox volume occupied by the cloudy air $\beta$; only cloudy points are included. Red line shows the average profile. The cloud fraction profile is shown on the righthand side of the panel with the blue line.

0 (homogeneous mixing) to 1 (extremely inhomogeneous mixing). As illustrated in Fig. 7, the model predicts the existence of the subgrid-scale mixing mostly within the cumulus layer and near the very stratocumulus top. This section presents statistical analysis of the model-predicted mixing characteristics in the simulation.

Figure 13 presents CFAD of the parameter $\alpha$ for the points undergoing subgrid-scale turbulent mixing. The number of points (as a fraction of all points at a given level) included in the analysis is shown on the right-hand sides of the panels. The red line shows the average profile. The profile is approximately constant across the cloud layer, except near the bottom and the top of the cloud field. Although the cloud fraction in the cumulus layer is small, the mixing events occur often: approximately half of the cloudy points within the cumulus layer experience turbulent mixing. The most frequent mixing scenario in the cumulus layer corresponds to $\alpha \approx 0.75$, but predicted values range from 0.3 to 0.9 . Mixing events are rare across most of the stratocumulus depth. Only near the cloud top do entrainment and mixing occur more frequently. The range of mixing scenarios near the cloud top is wide, between values close to 0 and values close to 1 , and the average is around 0.6.

Parameter $\alpha$ depends on the characteristic time scales for the droplet evaporation, $\tau_{\text {evap }}$, and for the turbulent mixing, $\tau_{\text {mix }}$. Appendix A presents formulas that are used to locally derive $\alpha$ from $\tau_{\text {evap }}$ and $\tau_{\text {mix }}$, and the time scales from the model variables (more in-depth discussion is provided in JGMP13). Figures 14 and 15 show scatter diagrams of model variables (in appropriate powers; see Appendix A) that determine the actual values of the $\tau_{\text {evap }}$ and $\tau_{\text {mix }}$ at the height of $500 \mathrm{~m}$ (i.e., within the cumulus layer) and $1200 \mathrm{~m}$ (i.e., near 

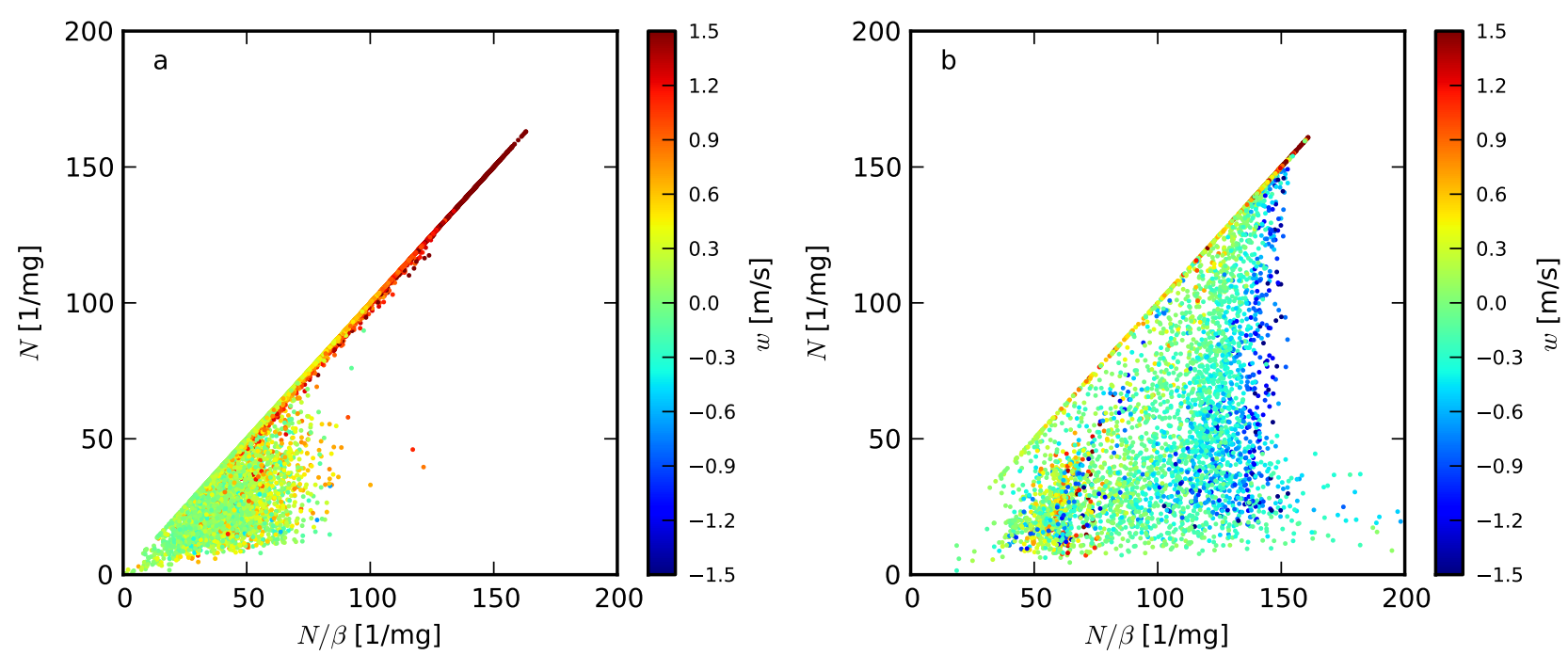

Fig. 11. Scatter diagram of the gridbox mean versus local droplet concentration $(N$ versus $N / \beta)$ for cloudy gridpoint at height of $500 \mathrm{~m}$ (a) and $1200 \mathrm{~m}(\mathbf{b})$. Color marks the vertical velocity, and the color scale is shown to the right of each panel.

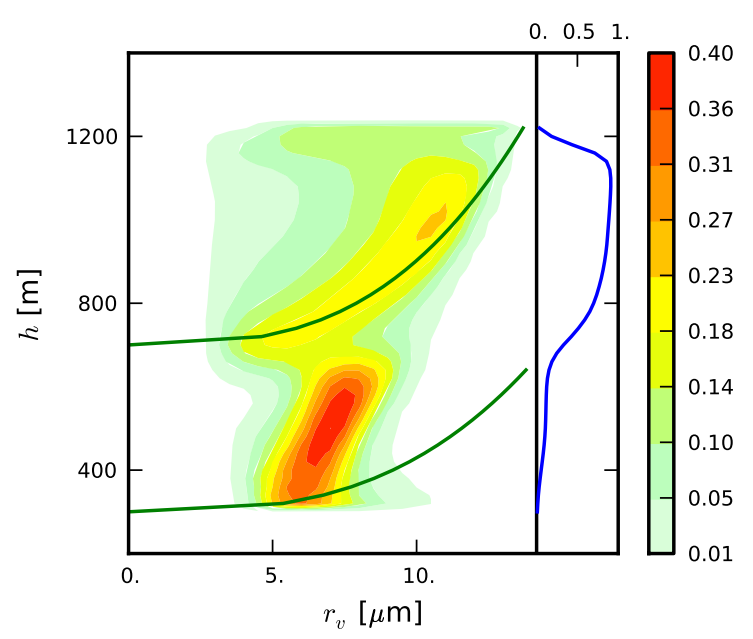

Fig. 12. CFAD of the droplet mean volume radius $r_{\mathrm{v}}$; only cloudy points are included. Green lines show the adiabatic values of the radius assuming the cloud base height and the adiabatic droplet concentration of $300 \mathrm{~m}^{2}$ and $60 \mathrm{mg}^{-1}$ for the cumulus layer, and $700 \mathrm{~m}$ and $90 \mathrm{mg}^{-1}$ for the stratocumulus layer. The cloud fraction profile is shown on the right-hand side of the panel with the blue line.

the stratocumulus top), respectively. Values of the characteristic time scales are indicated by colors and black isolines.

There are systematic differences between Figs. 14 and 15. For instance, there is a larger number of points with longer mixing time scale $\tau_{\text {mix }}$ for the cumulus layer. This comes from lower TKE and larger filament width $\lambda$ predicted by the model. Similarly, the differences in the evaporation time scale $\tau_{\text {evap }}$ come from the combination of lower relative humidity $\mathrm{RH}_{\mathrm{d}}$ and larger droplet radii near the stratocumulus top. Both variables have stronger variation in the stratocumulus case. Note that $\mathrm{RH}_{\mathrm{d}}$ is typically quite high ( 0.9 and

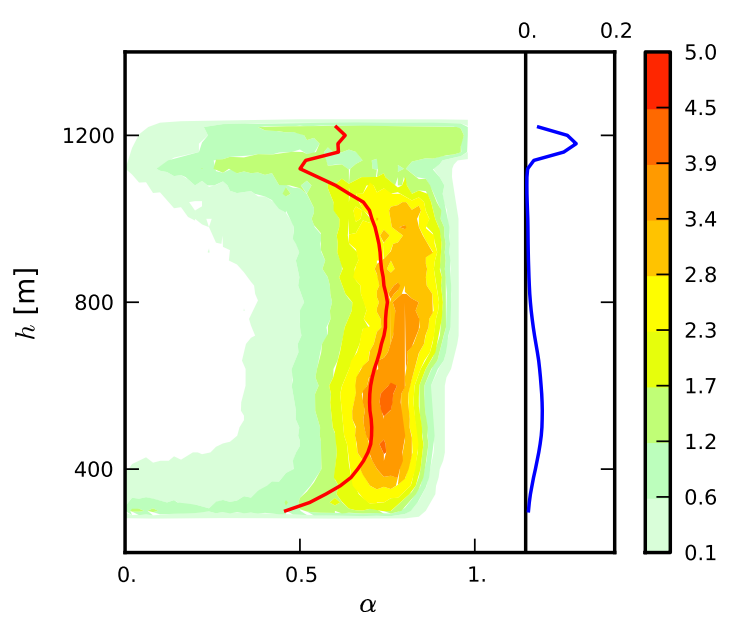

Fig. 13. CFAD of the parameter $\alpha$. Only cloudy points where the subgrid-scale mixing takes place are included. Red line shows the average profile. The frequency of mixing events (i.e., the number of points undergoing turbulent mixing divided by total number of points at each level) is shown on the right-hand side with the blue line.

above, so that $1 /\left(1-\mathrm{RH}_{\mathrm{d}}\right)$ is larger than 10$)$, but it is shifted towards lower humidities for the stratocumulus layer. This is consistent with the fact that stratocumulus entrains drier air from above the inversion.

Mixing characteristics are often discussed applying the diagram introduced in Burnet and Brenguier (2007) and subsequently used in observational cloud studies focusing on the microphysical structures of clouds (e.g., Lehmann et al., 2009); see discussion in Sect. 5 of JGMP13. In the diagram, the mean volume radius of cloud droplets cubed $r_{\mathrm{v}}^{3}$ is plotted as a function of the droplet concentration $N$. We refer to the 

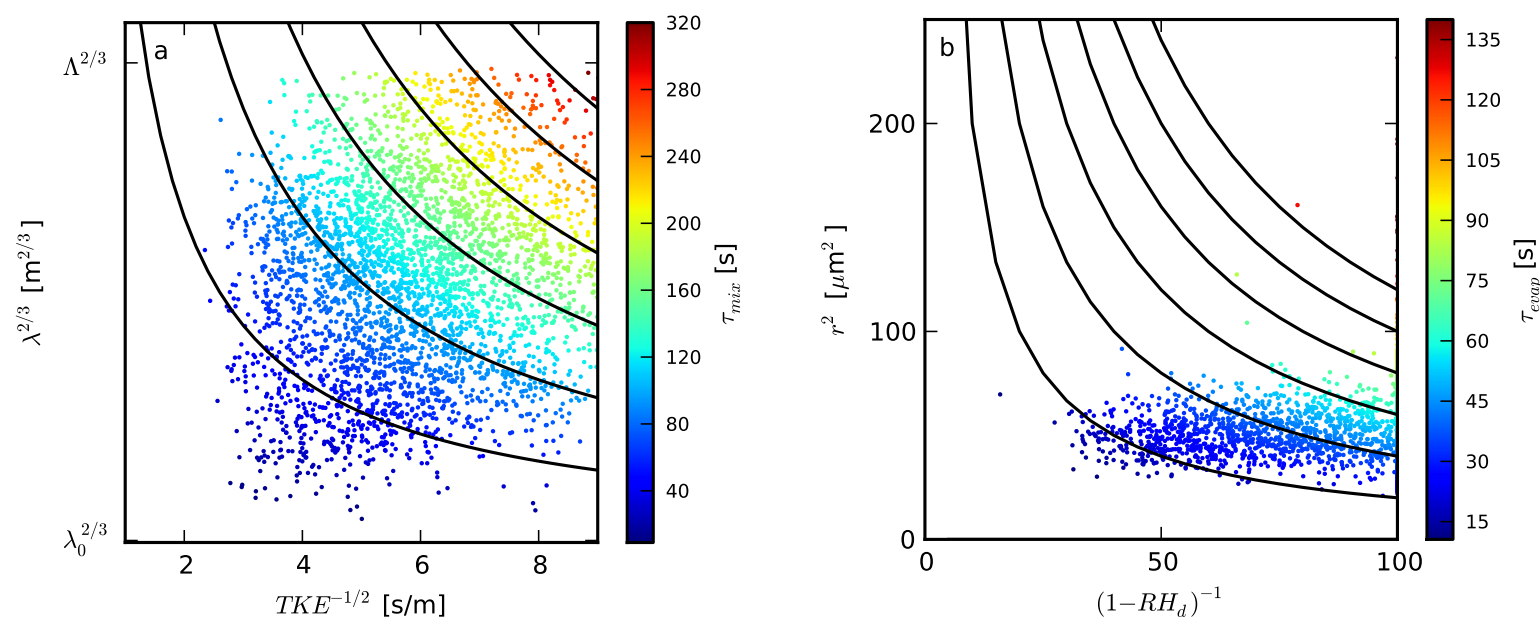

Fig. 14. Scatter diagrams of model variables (in appropriate powers; see Appendix A) that determine values of the $\tau_{\text {mix }}$ (a) and $\tau_{\text {evap }}$ (b) at the height of $500 \mathrm{~m}$ (i.e., within the cumulus layer). Color scale and black lines mark values of the time scales.
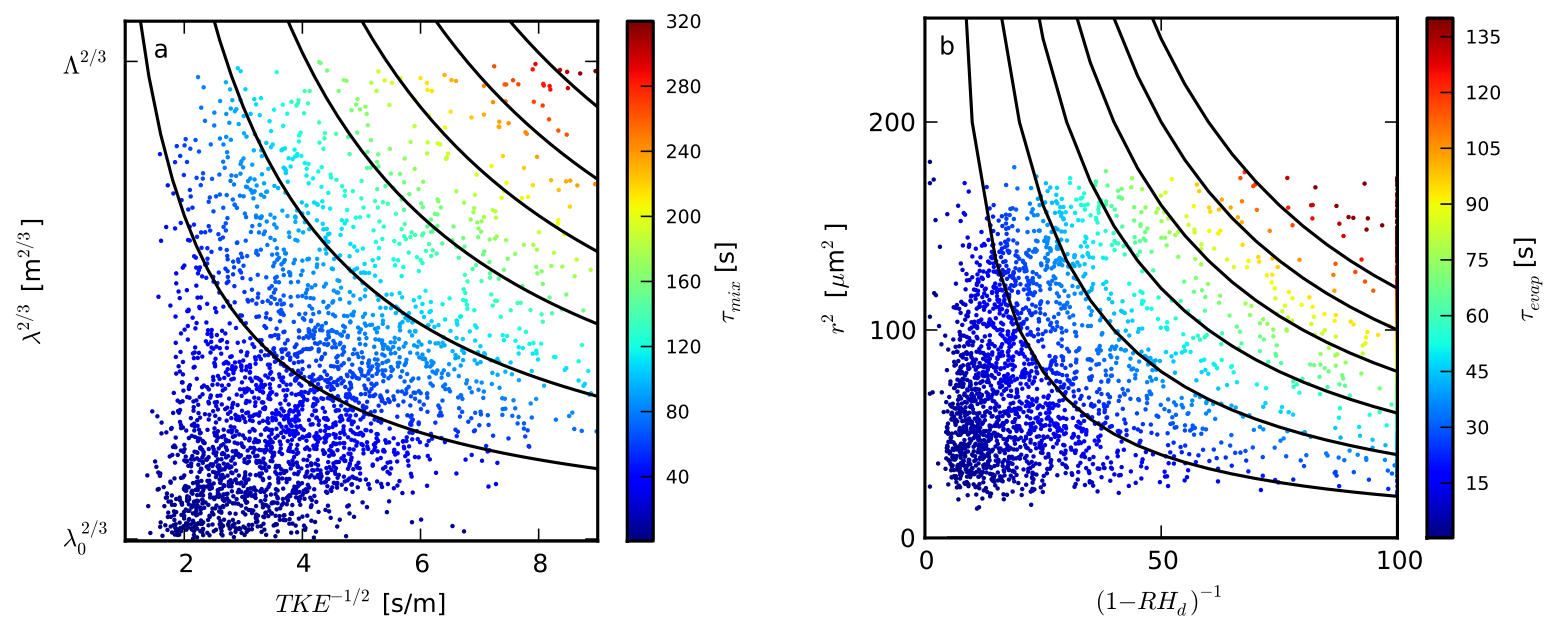

Fig. 15. As Fig. 14 but at the height of $1200 \mathrm{~m}$ (i.e., at the top of the stratocumulus layer).

diagram as $N-r_{\mathrm{v}}^{3}$ diagram and focus on the regions where significant entrainment and mixing take place, that is, the cumulus layer and near the very top of the stratocumulus. Unfortunately, the number of datapoints in the aircraft data is relatively small because of short periods the aircraft spent at specific heights; see Fig. 2. It follows that $N-r_{\mathrm{v}}^{3}$ diagrams from observations do not allow a meaningful comparison with model results.

Figure 16 shows the $N-r_{\mathrm{v}}^{3}$ diagrams for the simulated cumulus clouds (at height of $500 \mathrm{~m}$ ) and near the stratocumulus top (at height of $1200 \mathrm{~m}$ ). Each point represents a gridpoint datum from all cloudy points for $30 \mathrm{~min}$ of simulation starting at $3.5 \mathrm{~h}$. We use the local droplet concentration $N / \beta$ as in JGMP13. In addition, we apply color to mark the vertical velocity. Black lines in the figures show isolines of LWC; the thicker lines represent estimations of the adiabatic LWC. Red lines indicate extremely inhomogeneous mixing and blue lines indicate homogeneous mixing for different rel- ative humidities of entrained air. For the cumulus, the cloud base that determines the adiabatic LWC is chosen at height of $300 \mathrm{~m}$; the adiabatic droplet concentration is selected as $160 \mathrm{mg}^{-1}$. These values set the starting point for the homogeneous and extremely inhomogeneous mixing lines, marked as the star on the $N-r_{\mathrm{v}}^{3}$ diagram. Similarly to JGMP13 (see Fig. 10 therein), colors representing significant updrafts seem to be aligned in vertical belts; that is, they represent similar droplet concentrations across a range of LWC. Vertical velocities are higher for volumes with higher droplet concentration, perhaps because of the dependence of droplet activation on the vertical velocity. For the stratocumulus top (Fig. 16b), the two starting points for the mixing lines are selected, representing either the stratocumulus cloud base at $700 \mathrm{~m}$ or the cloud base at $300 \mathrm{~m}$ for cumuli that penetrate into the stratocumulus layer. The stratocumulus top $N-r_{\mathrm{v}}^{3}$ diagram shows that many points (around 20\%) have LWC higher than the adiabatic value for stratocumulus, which can be explained 
by cumulus penetrations. The points with the highest LWC have also relatively large vertical velocities and large droplet number concentrations. This is because only the most vigorous cumuli are able to penetrate into stratocumulus and the largest vertical velocities lead to the highest concentrations of activated cloud droplets. However, the points with high droplet concentration and reduced LWC are typically associated with downdrafts (i.e., blue colors), in contrast to similar points in the cumulus layer. These points likely represent early stages of entrainment and mixing and correspond to dark blue points in Fig. 11b.

\section{Simulations with the standard double-moment LES model}

To put the results of the previous sections into a broader context, we perform additional simulations with the standard LES configuration of the EULAG model. The standard LES model excludes the subgrid-scale stirring scheme (i.e., cloud water is evaporated as dictated by the grid-scale fields), and no prediction of the homogeneity of the subgrid-scale mixing is available. The latter implies that the parameter $\alpha$ in Eq. (A1) has to be prescribed. Two additional simulations are performed, assuming either $\alpha=0$ (i.e., always homogeneous mixing for the evaporation resulting from the subgridscale mixing) or $\alpha=1$ (extremely inhomogeneous mixing). Except for these differences, the standard EULAG simulations feature the same setup as the simulation discussed in the previous sections.

As far as bulk properties of the cloud field are concerned, the additional simulations provide results broadly consistent with those discussed in Sect. 4. For instance, the cloud fraction profiles and CFADs of various quantities differ only in some details throughout the cloud field depth with more noticeable differences near the stratocumulus top (not shown). Similarly to the results in Slawinska et al. (2012), the $\alpha=$ 1 simulations (i.e., extremely inhomogeneous subgrid-scale mixing) feature slightly lower mean in-cloud droplet concentration when compared to the $\alpha=0$ (homogeneous mixing) simulation.

In shallow-convection cloud field simulations reported in Grabowski (2007) and Jarecka et al. (2009), incorporating the delay of the droplet evaporation results in a deeper cloud field, as documented by the profiles of the cloud fraction, e.g., Fig. 9 in Grabowski (2007). For the stratocumulus, incorporating the delay may lead to differences in the STBL entrainment rate because buoyancy reversal associated with droplet evaporation plays an important role in the stratocumulus entrainment (e.g., Kurowski et al., 2009, and references therein). The key parameter determining the impact of buoyancy reversal is the relative change of the equivalent potential temperature $\theta_{\mathrm{e}}$ across the boundary layer inversion when compared to the change of the total water $q_{\mathrm{t}}$ (e.g., Kuo and Schubert, 1988, see Fig. 1 in particular). The initial con- ditions for the simulations described in this paper give the $\theta_{\mathrm{e}}$ increase across the inversion of about $5 \mathrm{~K}$, and the $q_{\mathrm{t}}$ decrease of about $2 \mathrm{~g} \mathrm{~kg}^{-1}$. It implies that the case considered here resides in the stable part of Fig. 1 of Kuo and Schubert (1988) and only small impact of delay of cloud evaporation is anticipated. This indeed seems to be the case as the change of the inversion height during the course of the standard LES simulations is almost identical to the change shown in Fig. 6, that is, around $80 \mathrm{~m}$ during $6 \mathrm{~h}$ of the simulation.

Significant differences between the simulations are observed near the top of stratocumulus where the most pronounced entrainment and mixing takes place. Figure $17 \mathrm{com}-$ pares the $N-r^{3}$ diagrams, in the format of Fig. 16 (but using the mean cloud droplet concentration $N$ since $\beta$ is not predicted), for the $\alpha=1$ and $\alpha=0$ standard LES simulations. As one might anticipate, the patterns for the two simulations indeed correspond to the homogeneous and extremely inhomogeneous mixing scenarios. As a sidenote, if Fig. 16b (i.e., the $N-r_{\mathrm{v}}^{3}$ diagram for the stratocumulus top) is replotted using the mean concentration $N$ rather than the local concentration $N / \beta$, then the pattern is in between those shown in Fig. 17 as one might expect based on the predicted mixing scenarios.

In summary, as far as the cloud dynamics is concerned, the new LES model produces results close to the standard model in the particular case considered here. However, the new model provides additional insights into the microphysical processes associated with entrainment and mixing as illustrated by Figs. 11 and 16, and into differences between cumulus and stratocumulus entrainment in particular.

\section{Conclusions}

This paper presents aircraft observations and LES modeling of 15 May boundary-layer clouds over the North Sea observed during the EUCAARI-IMPACT field campaign. An almost-solid stratocumulus deck was present in the upper part of the relatively deep, weakly decoupled marine boundary layer. Small cumuli, with a cloud fraction of $\sim 10 \%$, were sampled beneath the stratocumulus. The two cloud formations featured distinct microphysical characteristics. Small cumuli were significantly diluted and featured low LWC, typically below $0.2 \mathrm{~g} \mathrm{~kg}^{-1}$, droplet radii between 2 and $8 \mu \mathrm{m}$, and a wide rage of droplet concentrations, from a few to about $100 \mathrm{mg}^{-1}$ (when sampled at $1 \mathrm{~Hz}$ ). In contrast, stratocumulus was only weakly diluted, $1 \mathrm{~Hz}$ droplet concentrations ranged between 50 and $150 \mathrm{mg}^{-1}$ and were approximately height-independent, except near the cloud top where significant dilution and lower droplet concentrations were observed.

To simulate the observed cloud field sampled, model setup was developed based on the available observations and trialand-error test simulations. The LES model used in this study is based on the EULAG anelastic fluid flow solver 

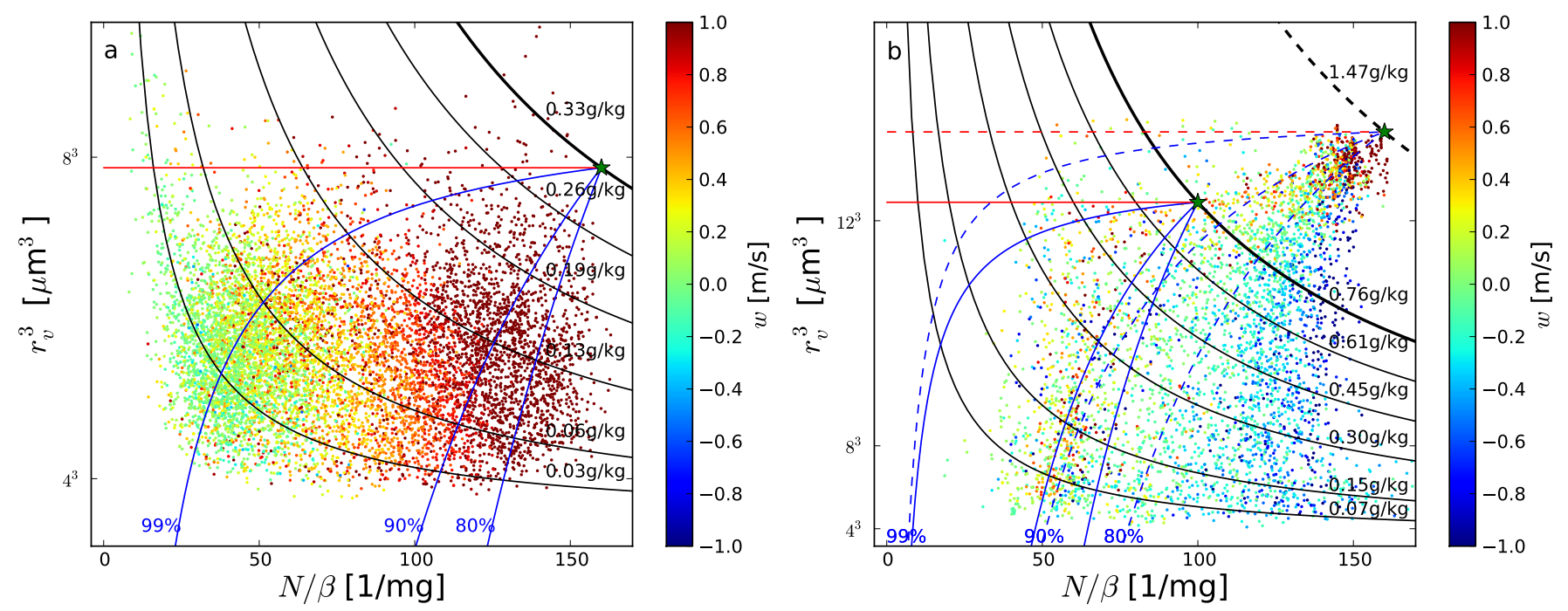

Fig. 16. The $N-r_{\mathrm{v}}^{3}$ diagrams: (a) at the height of $500 \mathrm{~m}$ (i.e., within the cumulus layer); (b) at the height of $1200 \mathrm{~m}$ (i.e., at the stratocumulus top). Black lines show isolines of LWC; the thicker lines represent estimations of the adiabatic LWC. Red lines indicate extremely inhomogeneous mixing and blue lines indicate homogeneous mixing for different relative humidities of entrained air. The starting points for the mixing lines are marked as the green stars. For the stratocumulus, two starting points are selected to represent the cumuli that penetrate into the stratocumulus layer. Color marks the vertical velocity and the color scale is shown to the right of each panel.
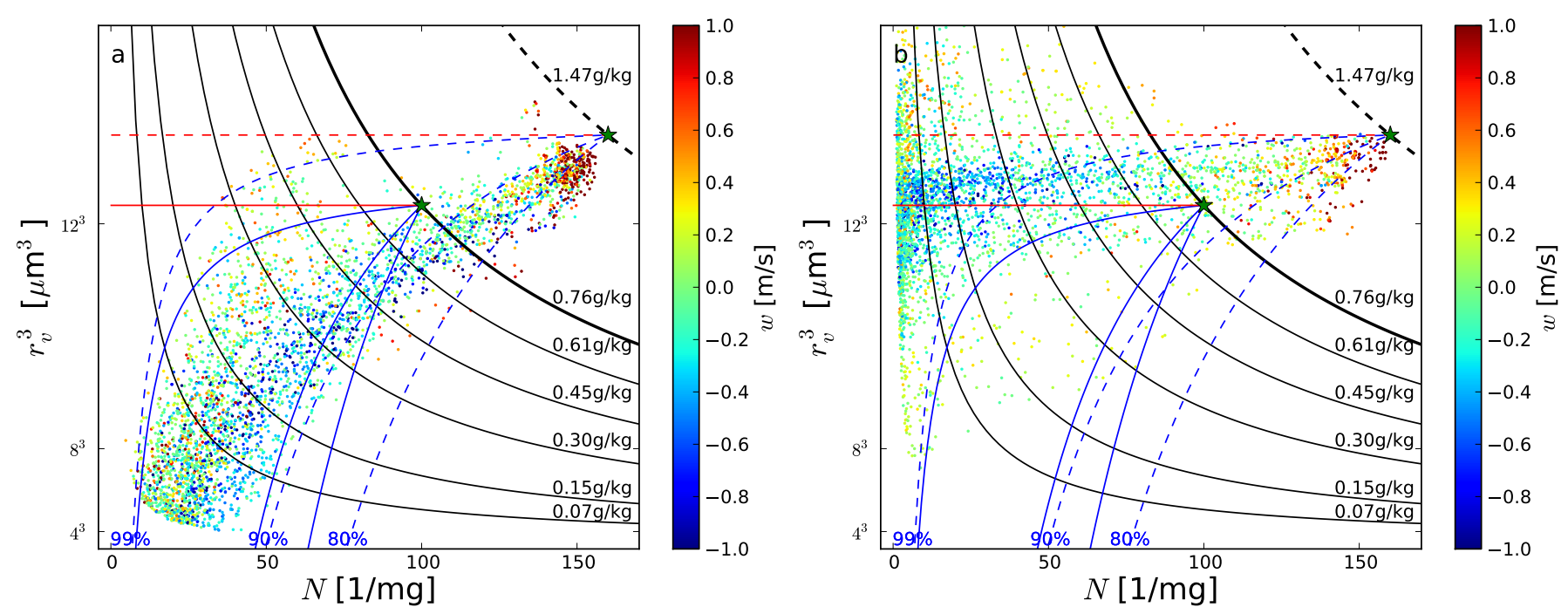

Fig. 17. The $N-r_{\mathrm{v}}^{3}$ diagrams from simulations applying the standard LES model and at the height of $1200 \mathrm{~m}$ (i.e., at the stratocumulus top). Panel $(\mathbf{a} / \mathbf{b})$ is for the simulation assuming $\alpha$ of 0/1. Black lines show isolines of LWC; the thicker lines represent estimations of the adiabatic LWC. Red lines indicate extremely inhomogeneous mixing and blue lines indicate homogeneous mixing for different relative humidities of entrained air. The starting points for the mixing lines are marked as the green stars. Two starting points are selected to represent the cumuli that penetrate into the stratocumulus layer. Color marks the vertical velocity and the color scale is shown to the right of each panel.

and features the double-moment warm-rain microphysics scheme. The model is used either in the standard configuration (as in Slawinska et al., 2012) or in the novel configuration developed in JGMP13. The new configuration includes the delay of cloud water evaporation resulting from the subgrid-scale turbulent entrainment (Grabowski, 2007; Jarecka et al., 2009) and prediction of homogeneity of the subgrid-scale mixing between the cloud and its cloud-free environment. The homogeneity of the subgrid-scale mixing in the double-moment microphysics scheme is controlled by a single parameter $\alpha$, with the range of values between 0 to 1. The limiting values represent the homogeneous and the extremely inhomogeneous mixing, respectively. In the standard LES model, the parameter $\alpha$ needs to be prescribed. In the new model, it is predicted as a function of the characteristic time scales for the droplet evaporation and for the 
turbulent homogenization. These scales are derived locally from the subgrid-scale turbulent kinetic energy, spatial scale of cloudy filaments, the mean cloud droplet radius, and the humidity of the cloud-free air entrained into the cloud. All these variables are predicted by the new model.

Model simulations reproduce relatively well the stratocumulus-over-cumulus cloud structure as well as most of the contrasting macrophysical and microphysical characteristics of the two cloud layers. The subgrid-scale mixing is predicted to be on average quite inhomogeneous. However, local variations of the parameter $\alpha$ at a given height are large and cover almost the entire range. Mixing events are predicted mostly in the cumulus layer and near the top of the stratocumulus. The mixing close to the stratocumulus top is on average more homogeneous than in the cumulus layer, and the distribution of the local $\alpha$ values is wider. The differences are caused mostly by the wider range of the mean cloud droplet radius and the humidity of the entrained air, as well as the higher values of subgrid-scale TKE near the stratocumulus top.

The $N-r_{\mathrm{v}}^{3}$ diagram (Burnet and Brenguier, 2007) shows that the highest local droplet concentrations in the cumulus layer correspond to the largest vertical velocities regardless of the cloud dilution and the mean volume radius. This pattern resembles the one in shallow cumuli simulations reported in JGMP13 (see Fig. 10 therein). The most likely explanation involves the dependence of the droplet activation on the vertical velocity. For the stratocumulus top, the diagram shows the presence of high-LWC cloudy volumes featuring high droplet concentrations that can only come from cumuli penetrating into stratocumulus. In contrast to the cumulus layer, high droplet concentration in diluted cloudy volumes near the stratocumulus top are typically associated with downdrafts. Arguably, these volumes represent initial stages of entrainment and mixing, where the close-to-adiabatic stratocumulus air impinges upon the inversion, mixes with the cloud-free air from the inversion layer, and is forced back into the main stratocumulus deck.

As far as cloud dynamics is concerned, the standard model results are broadly consistent with results from the new model. In particular, the boundary-layer entrainment rate (as measured by the rate of increase of the inversion height) is approximately the same in the two model simulations. The $N-r_{\mathrm{v}}^{3}$ diagrams for the two standard simulations show patterns consistent with the assumed mixing scenarios (i.e., $\alpha=1$ or $\alpha=0$ ). This highlights the significance of the representation of microphysical transformations associated with the subgrid-scale entrainment and mixing near the simulated stratocumulus top.

The modeling results discussed in this paper call for follow-up simulations. First, since the spatial resolution of current simulations is relatively low, higher-resolution simulations would be desirable. Second, the lack of significant differences in cloud properties between the standard model and the new model suggests that a similar study, focusing on dynamical aspects, should be conducted using STBL conditions susceptible to strong buoyancy reversal, for instance, as in the DYCOMS case (Stevens et al., 2005).

\section{Appendix A}

\section{Summary of model formulas determining the homogeneity of mixing}

Homogeneity of the subgrid-scale turbulent mixing in the double-moment microphysics scheme is determined by the parameter $\alpha$. This parameter is used to calculate the final droplet concentration after entrainment and turbulent mixing according to Eq. (11) in Morrison and Grabowski (2008):

$N^{\mathrm{f}}=N^{i}\left(\frac{q_{\mathrm{c}}^{\mathrm{f}}}{q_{\mathrm{c}}^{i}}\right)^{\alpha}$,

where $q_{\mathrm{c}}^{i}$ and $N^{i}$ are values of the cloud water mixing ratio and droplet concentration before including effects of evaporation due to the subgrid-scale mixing. These values include all other processes, such as the resolved (advective) and parameterized (subgrid-scale) transport and evaporation due to the advective changes of thermodynamic properties, the vertical advection in particular; $q_{\mathrm{c}}^{\mathrm{f}}$ is the final cloud water mixing ratio (i.e., after the microphysical adjustment). Note that, in the Morrison and Grabowski (2008) scheme, the microphysical adjustment of the cloud water mixing ratio $q_{\mathrm{c}}$ takes place before adjusting $N$, and it is dictated by the predicted supersaturation and characteristics of the cloud droplet population (i.e., the droplet concentration and size). In the model used here, it also depends on the subgrid-scale structure (i.e., scale of cloudy filaments $\lambda$ and cloudy fraction of the gridbox $\beta$ ) as explained in Sect. 3. Finally, $N^{\mathrm{f}}$ is the final droplet concentration after microphysical adjustment due to the subgridscale evaporation, and it depends on the $\alpha$ value. The parameter $\alpha$ varies from 0 for the case of the homogeneous mixing (i.e., no change to $N$ ) to 1 for the extremely inhomogeneous mixing (i.e., when $N$ changes in the same proportion as $q_{\mathrm{c}}$ and thus the mean volume radius remains unchanged).

To predict the local value of the parameter $\alpha$, we first relate it to the slope $\delta$ on the diagram applied in Andrejczuk et al. $(2004,2006)$. In this diagram, the total number of droplets is plotted against the mean volume radius cubed, similarly to the diagram used in Burnet and Brenguier (2007). The vertical line (reduction of the number of droplets without changing the size; $\delta \rightarrow \infty$ ) implies extremely inhomogeneous mixing. The homogeneous mixing corresponds to the horizontal line (i.e., changing droplet size without changing the number of droplets; $\delta=0$ ). The slope $\delta$ is related to the parameter $\alpha$ in Eq. (A1) as

$\alpha=\frac{\delta}{1+\delta}$. 
Based on a large set of DNS simulations, the $\delta$ can be assumed to be approximately equal to the ratio of the time scales for turbulent homogenization and droplet evaporation (see Fig. 2 in Andrejczuk et al., 2009):

$\delta \approx \frac{\tau_{\mathrm{mix}}}{\tau_{\mathrm{evap}}}$,

where $\tau_{\text {mix }}$ and $\tau_{\text {evap }}$ are turbulent mixing and droplet evaporation time scales respectively. The turbulent homogenization time scale, following Andrejczuk et al. (2009), is approximated by the eddy turnover time (e.g., Jensen and Baker, 1989):

$\tau_{\operatorname{mix}}=\lambda / u(\lambda)$

where $u(\lambda)$ is the characteristic velocity at the filament scale $\lambda$. It can be related to the model-predicted $\operatorname{TKE}(E)$ as $u(\lambda)=$ $(E)^{1 / 2}(\lambda / \Lambda)^{1 / 3}$. This relationship assumes the inertial range scaling for subgrid-scale turbulence and considers TKE to be dominated by the eddies of scale $\Lambda$ [i.e., $u(\Lambda) \approx(E)^{1 / 2}$ ]. The droplet evaporation time scale is estimated as

$\tau_{\text {evap }}=\frac{r^{2}}{A\left(1-\mathrm{RH}_{\mathrm{d}}\right)}$,

where $r$ is the mean volume radius of cloud droplets, $\mathrm{RH}_{\mathrm{d}}$ is the relative humidity of the cloud-free portion of the gridbox, and $A \approx 10^{-10} \mathrm{~m}^{2} \mathrm{~s}^{-1}$ is the constant in the droplet diffusional growth equation (i.e., $\mathrm{d} r / \mathrm{d} t=A S / r$, where $S=$ $\mathrm{RH}-1$ is the supersaturation). $\mathrm{RH}_{\mathrm{d}}$ can be estimated using the mean (model-predicted) relative humidity of the gridbox $\mathrm{RH}$ and assuming that the cloudy part of the gridbox is saturated. These assumptions lead to

$\mathrm{RH}_{\mathrm{d}}=\frac{\mathrm{RH}-\beta}{1-\beta}$.

Acknowledgements. EUCAARI-IMPACT data were provided by CNRM Meteo-France (Fred Burnet, Bruno Piguet and Vincent Puygrenier). D. Jarecka would like to thank Joanna Slawinska for her assistance with the EULAG model, Hugh Morrison for his assistance with the double-moment microphysics scheme and Sylwester Arabas for his assistance with the experimental data. D. Jarecka and H. Pawlowska were partially supported by the European Union 6 FP IP EUCAARI (European Integrated Project on Aerosol Cloud Climate and Air Quality Interactions) no. 036833-2 and the Polish MNiSW grant 396/6/PR UE/2007/7. D. Jarecka was additionally supported by the Polish MNiSW grant no. N N307 128038. D. Jarecka and W. W. Grabowski were also partially supported by the NOAA grant NA08OAR4310543, DOE ARM grant DE-FG02-08ER64574, and the NSF Science and Technology Center for Multiscale Modeling of Atmospheric Processes (CMMAP), managed by Colorado State University under cooperative agreement ATM-0425247. A. A. Wyszogrodzki's work was supported by NSF-OCI grants 0904599 and 0904449. Computer time at NCAR and University of Colorado Boulder was provided by NSF MRI grants CNS-0421498, CNS-0420873, CNS0420985, and CNS-0821794, NSF sponsorship of the National Center for Atmospheric Research, the University of Colorado, and a grant from the IBM Shared University Research (SUR) program. National Center for Atmospheric Research is sponsored by the National Science Foundation.

Edited by: V.-M. Kerminen

\section{References}

Andrejczuk, M., Grabowski, W. W., Malinowski, S. P., and Smolarkiewicz, P. K.: Numerical Simulation of Cloud-Clear Air Interfacial Mixing, J. Atmos. Sci., 61, 1726-1739, doi:10.1175/1520-0469(2004)061<1726:NSOCAI>2.0.CO;2, 2004.

Andrejczuk, M., Grabowski, W. W., Malinowski, S. P., and Smolarkiewicz, P. K.: Numerical Simulation of Cloud-Clear Air Interfacial Mixing: Effects on Cloud Microphysics, J. Atmos. Sci., 63, 3204-3225, doi:10.1175/JAS3813.1, 2006.

Andrejczuk, M., Grabowski, W. W., Malinowski, S. P., and Smolarkiewicz, P. K.: Numerical Simulation of Cloud-Clear Air Interfacial Mixing: Homogeneous versus Inhomogeneous Mixing, J. Atmos. Sci., 66, 2493-2500, doi:10.1175/2009JAS2956.1, 2009.

Baker, M. B. and Latham, J.: The Evolution of Droplet Spectra and the Rate of Production of Embryonic Raindrops in Small Cumulus Clouds, J. Atmos. Sci., 36, 1612-1615, 1979.

Baker, M. B., Corbin, R. G., and Latham, J.: The influence of entrainment on the evolution of cloud droplet spectra: I. A model of inhomogeneous mixing, Q. J. Roy. Meteor. Soc., 106, 581-598, doi:10.1002/qj.49710644914, 1980.

Brenguier, J.-L., Bourrianne, T., Coelho, A. A., Isbert, J., Peytavi, R., Trevarin, D., and Weschler, P.: Improvements of Droplet Size Distribution Measurements with the Fast-FSSP (Forward Scattering Spectrometer Probe), J. Atmos. Ocean. Tech., 15, 1077-1090, doi:10.1175/15200426(1998)015<1077:IODSDM>2.0.CO;2, 1998.

Bretherton, C. S. and Pincus, R.: Cloudiness and Marine Boundary Layer Dynamics in the ASTEX Lagrangian Experiments. Part I: Synoptic Setting and Vertical Structure, J. Atmos. Sci., 52, 2707-2723, doi:10.1175/15200469(1995)052<2707:CAMBLD>2.0.CO;2, 1995.

Burnet, F. and Brenguier, J.-L.: Observational Study of the Entrainment-Mixing Process in Warm Convective Clouds, J. Atmos. Sci., 64, 1995-2011, 2007.

Crumeyrolle, S., Weigel, R., Sellegri, K., Roberts, G., Gomes, L., Stohl, A., Laj, P., Bourianne, T., Etcheberry, J. M., Villani, P., Pichon, J. M., and Schwarzenboeck, A.: Impact of cloud processes on aerosol particle properties: results from two ATR-42 flights in an extended stratocumulus cloud layer during the EUCAARI campaign (2008), Atmos. Chem. Phys. Discuss., 11, 33229-33271, doi:10.5194/acpd-11-33229-2011, 2011.

de Roode, S. R. and Duynkerke, P. G.: Observed Lagrangian Transition of Stratocumulus into Cumulus during ASTEX: Mean State and Turbulence Structure, J. Atmos. Sci., 54, 2157-2173, 1997.

Grabowski, W. W.: Representation of Turbulent Mixing and Buoyancy Reversal in Bulk Cloud Models, J. Atmos. Sci., 64, 36663680, doi:10.1175/JAS4047.1, 2007. 
Grabowski, W. W. and Smolarkiewicz, P. K.: Two-TimeLevel Semi-Lagrangian Modeling of Precipitating Clouds, Mon. Weather Rev., 124, 487-497, doi:10.1175/15200493(1996)124<0487:TTLSLM>2.0.CO;2, 1996.

Jarecka, D., Grabowski, W. W., and Pawlowska, H.: Modeling of Subgrid-Scale Mixing in Large-Eddy Simulation of Shallow Convection, J. Atmos. Sci., 66, 2125-2133, doi:10.1175/2009JAS2929.1, 2009.

Jarecka, D., Grabowski, W. W., Morrison, H., and Pawlowska, H.: Homogeneity of the subgrid-scale turbulent mixing in large-eddy simulation of shallow convection, J. Atmos. Sci., doi:10.1175/JAS-D-13-042.1, in press, 2013.

Jensen, J. B. and Baker, M. B.: A Simple Model of Droplet Spectral Evolution during Turbulent Mixing, J. Atmos. Sci., 46, 2812-2829, doi:10.1175/15200469(1989)046<2812:ASMODS>2.0.CO;2, 1989.

Khairoutdinov, M. and Kogan, Y.: A New Cloud Physics Parameterization in a Large-Eddy Simulation Model of Marine Stratocumulus, Mon. Weather Rev., 128, 229-243, 2000.

Khvorostyanov, V. I. and Curry, J. A.: Aerosol size spectra and $\mathrm{CCN}$ activity spectra: Reconciling the lognormal, algebraic, and power laws, J. Geophys. Res., 111, 0148-0227, doi:10.1029/2005JD006532, 2006.

Kulmala, M., Asmi, A., Lappalainen, H. K., Baltensperger, U., Brenguier, J.-L., Facchini, M. C., Hansson, H.-C., Hov, Ø., O’Dowd, C. D., Pöschl, U., Wiedensohler, A., Boers, R., Boucher, O., de Leeuw, G., Denier van der Gon, H. A. C., Feichter, J., Krejci, R., Laj, P., Lihavainen, H., Lohmann, U., McFiggans, G., Mentel, T., Pilinis, C., Riipinen, I., Schulz, M., Stohl, A., Swietlicki, E., Vignati, E., Alves, C., Amann, M., Ammann, M., Arabas, S., Artaxo, P., Baars, H., Beddows, D. C. S., Bergström, R., Beukes, J. P., Bilde, M., Burkhart, J. F., Canonaco, F., Clegg, S. L., Coe, H., Crumeyrolle, S., D'Anna, B., Decesari, S., Gilardoni, S., Fischer, M., Fjaeraa, A. M., Fountoukis, C., George, C., Gomes, L., Halloran, P., Hamburger, T., Harrison, R. M., Herrmann, H., Hoffmann, T., Hoose, C., Hu, M., Hyvärinen, A., Hõrrak, U., Iinuma, Y., Iversen, T., Josipovic, M., Kanakidou, M., Kiendler-Scharr, A., Kirkevåg, A., Kiss, G., Klimont, Z., Kolmonen, P., Komppula, M., Kristjánsson, J.-E., Laakso, L., Laaksonen, A., Labonnote, L., Lanz, V. A., Lehtinen, K. E. J., Rizzo, L. V., Makkonen, R., Manninen, H. E., McMeeking, G., Merikanto, J., Minikin, A., Mirme, S., Morgan, W. T., Nemitz, E., O’Donnell, D., Panwar, T. S., Pawlowska, H., Petzold, A., Pienaar, J. J., Pio, C., Plass-Duelmer, C., Prévôt, A. S. H., Pryor, S., Reddington, C. L., Roberts, G., Rosenfeld, D., Schwarz, J., Seland, Ø., Sellegri, K., Shen, X. J., Shiraiwa, M., Siebert, H., Sierau, B., Simpson, D., Sun, J. Y., Topping, D., Tunved, P., Vaattovaara, P., Vakkari, V., Veefkind, J. P., Visschedijk, A., Vuollekoski, H., Vuolo, R., Wehner, B., Wildt, J., Woodward, S., Worsnop, D. R., van Zadelhoff, G.-J., Zardini, A. A., Zhang, K., van Zyl, P. G., Kerminen, V.-M., S Carslaw, K., and Pandis, S. N.: General overview: European Integrated project on Aerosol Cloud Climate and Air Quality interactions (EUCAARI) -integrating aerosol research from nano to global scales, Atmos. Chem. Phys., 11, 13061-13143, doi:10.5194/acp11-13061-2011, 2011.
Kuo, H.-C. and Schubert, W. H.: Stability of cloud-topped boundary layers, Q. J. Roy. Meteor. Soc., 114, 887-916, doi:10.1002/qj.49711448204, 1988.

Kurowski, M., P. Malinowski, S., and W. Grabowski, W.: A numerical investigation of entrainment and transport within a stratocumulus-topped boundary layer, Q. J. Roy. Meteor. Soc., 135, 77-92, doi:10.1002/qj.354, 2009.

Lehmann, K., Siebert, H., and Shaw, R. A.: Homogeneous and Inhomogeneous Mixing in Cumulus Clouds: Dependence on Local Turbulence Structure, J. Atmos. Sci., 66, 3641-3659, 2009.

Margolin, L. G., Smolarkiewicz, P. K., and Sorbjan, Z.: Largeeddy simulations of convective boundary layers using nonoscillatory differencing, Physica D, 133, 390-397, doi:10.1016/S01672789(99)00083-4, 1999.

Morrison, H. and Grabowski, W. W.: Comparison of Bulk and Bin Warm-Rain Microphysics Models Using a Kinematic Framework, J. Atmos. Sci., 64, 2839-2861, doi:10.1175/JAS3980, 2007.

Morrison, H. and Grabowski, W. W.: Modeling Supersaturation and Subgrid-Scale Mixing with Two-Moment Bulk Warm Microphysics, J. Atmos. Sci., 65, 792-812, doi:10.1175/2007JAS2374.1, 2008.

Prusa, J. M., Smolarkiewicz, P. K., and Wyszogrodzki, A. A.: EULAG, a computational model for multiscale flows, Comput. Fluids, 37, 1193-1207, doi:10.1016/j.compfluid.2007.12.001, 2008.

Puygrenier, V., Brenguier, J.-L., Burnet, F., Gomes, L., and Thouron, O.: LES Simulation of a Stratocumulus Diurnal Cycle, in: Proceedings of 2009 EUCAARI Annual Meeting, 275-278, 2010.

Sandu, I., Stevens, B., and Pincus, R.: On the transitions in marine boundary layer cloudiness, Atmos. Chem. Phys., 10, 2377-2391, doi:10.5194/acp-10-2377-2010, 2010.

Siebesma, A. P., Bretherton, C. S., Brown, A., Chlond, A., Cuxart, J., Duynkerke, P. G., Jiang, H., Khairoutdinov, M., Lewellen, D., Moeng, C.-H., Sanchez, E., Stevens, B., and Stevens, D. E.: A Large Eddy Simulation Intercomparison Study of Shallow Cumulus Convection, J. Atmos. Sci., 60, 1201-1219, doi:10.1175/1520-0469(2003)60<1201:ALESIS>2.0.CO;2, 2003.

Slawinska, J., Grabowski, W. W., Pawlowska, H., and Morrison, H.: Droplet activation and mixing in large-eddy simulation of a shallow cumulus field, J. Atmos. Sci., 69, 444-462, doi:10.1175/JAS-D-11-054.1, 2012.

Smolarkiewicz, P. K. and Margolin, L. G.: Onforward-in-time differencing for fluids: An Eulerian/semi-Lagrangian nonhydrostatic model for stratified flows., Atmos.-Ocean Special, 35, 127 152, 1997.

Stevens, B., Moeng, C.-H., Ackerman, A. S., Bretherton, C. S., Chlond, A., de Roode, S., Edwards, J., Golaz, J.-C., Jiang, H., Khairoutdinov, M., Kirkpatrick, M. P., Lewellen, D. C., Lock, A., Müller, F., Stevens, D. E., Whelan, E., and Zhu, P.: Evaluation of Large-Eddy Simulations via Observations of Nocturnal Marine Stratocumulus, Mon. Weather Rev., 133, 1443-1462, 2005. 